\title{
Improved design of InGaP/GaAs//Si tandem solar cells
}

\author{
Santiago Torres-Jaramillo ${ }^{1}$, Roberto Bernal-Correa ${ }^{1}$, and Arturo Morales-Acevedo ${ }^{2, *}$ \\ ${ }^{1}$ Grupo de Investigación en Ciencias de la Orinoquia, Universidad Nacional de Colombia Sede Orinoquia, Arauca, Colombia \\ ${ }^{2}$ Centro de Investigación y de Estudios Avanzados del IPN, Electrical Engineering Department-SEES, Ciudad de México, \\ México
}

Received: 19 June 2020 / Received in final form: 16 January 2021 / Accepted: 19 January 2021

\begin{abstract}
Optimizing any tandem solar cells design before making them experimentally is an important way of reducing development costs. Hence, in this work, we have used a complete analytical model that includes the important effects in the depletion regions of the III-V compound cells in order to simulate the behavior of two and four-terminal InGaP/GaAs//Si tandem solar cells for optimizing them. The design optimization procedure is described first, and then it is shown that the expected practical efficiencies at 1 sun (AM1.5 spectrum) for both two and four-terminal tandem cells can be around $40 \%$ when the appropriate thickness for each layer is used. The optimized design for both structures includes a double $\mathrm{MgF}_{2} / \mathrm{ZnS}$ anti-reflection layer (ARC). The results show that the optimum thicknesses are $130\left(\mathrm{MgF}_{2}\right)$ and $60 \mathrm{~nm}(\mathrm{ZnS})$, respectively, while the optimum InGaP thickness is $220 \mathrm{~nm}$ and GaAs optimum thickness is $1800 \mathrm{~nm}$ for the four-terminal tandem on a HIT silicon solar cell (with total tandem efficiency around 39.8\%). These results can be compared with the recent record experimental efficiency around $35.9 \%$ for this kind of solar cells. Therefore, triple junction InGaP/GaAs// Silicon tandem solar cells continue being very attractive for further development, using high efficiency HIT silicon cell as the bottom sub-cell.
\end{abstract}

Keywords: III-V/Si tandem solar cells / hybrid tandem/multi-junction solar cells / anti-reflecting coating

\section{Introduction}

Over the last decades, photovoltaic energy has become one important contributor to the current energy production, around $1.7 \%$ of the world power supply [1]. Thin film solar cells based on CdTe, copper indium gallium selenide (CIGS) or amorphous silicon have been developed as a cheaper alternative to crystalline silicon cells [2-7]. On the other hand, tandem cells, or multi-junction cells, as they are also called, were originally used for spacecrafts, where materials such as gallium-arsenide (GaAs) and germanium (Ge) substrates were combined for the first time to achieve high efficiencies [8-10]. In order to create cost-effective tandem cells, the most obvious way is to add new materials on top of conventional single-junction cells based on silicon or thin film materials such as CIGS. Adding an additional junction layer to industrial PV cells can be the cheapest way to further improve photovoltaic efficiency [11]. Specifically, a very attractive alternative for having very high efficiency solar cells is the coupling of different generation solar cells (e.g. Perovskite/CIGS, III-V/Si)

\footnotetext{
* e-mail: amorales@solar.cinvestav.mx
}

$[12,13]$. Experimentally, the new technologies that couple two or more solar cell junctions based on III-V materials and $\mathrm{Si}$, have exceeded the efficiency limit for a single junction, reaching efficiencies around 36\%. This achievement is due to the optimization of parameters such as reflectance and thickness of each junction material [14]. In this regard, the use of HIT (HJ) silicon solar cells, as bottom cells, is important because they have been reported to be the record efficiency silicon cells [1]. Besides, III-V semiconductor multi-junction solar cells are attractive because they have achieved more than $40 \%$ under solar concentration [15].

Essig et al. [14] have demonstrated experimental conversion efficiencies of $32.5 \%$ and $32.8 \%$ (AM1.5) for III-V//Si two-junction solar cells based on mechanical stacking of GaInP-GaAs//Si cells. In addition, they showed a three-junction $\mathrm{GaInP} / \mathrm{GaAs} / / \mathrm{Si}$ cells with a record $35.9 \%$ efficiency All of the above was achieved with the use of $\mathrm{ZnS} / \mathrm{MgF}_{2}$-based anti-reflective coatings to prevent optical losses in the device [14]. In this work, it is shown that improved designs of two-terminal and fourterminal three-junction $\mathrm{InGaP} / \mathrm{GaAs} / / \mathrm{Si}$ tandem solar cells with a double anti-reflection coating (Fig. 1) can achieve even higher efficiencies, around $39.8 \%$, at one sun 

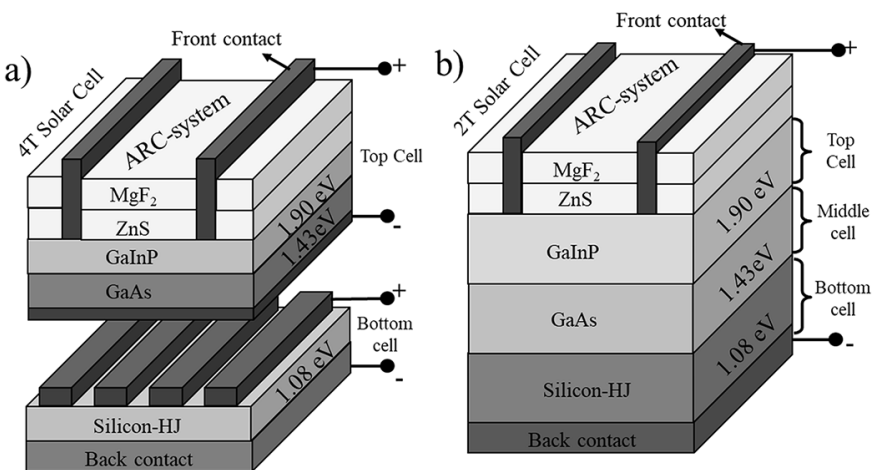

Fig. 1. (a) Schematics of a four-terminal InGaP/GaAs//Si-HJ solar cell. The top sub-cell is formed by the two-terminal III-V tandem. (b) Schematics of a two-terminal InGaP/GaAs/Si-HJ solar cell. In this case, the tunnel junctions are not depicted, nor they are considered for the calculations.

(AM1.5). The model used for the III-V solar sub-cells includes the effects related to the carrier recombination within the space-charge regions which cause the reduction of both the illumination current and the open-circuit voltage of very thin solar cells. Therefore, the calculations and design results are more realistic than those typically reported without considering these space-charge effects.

\section{Four-terminal tandem solar cells}

In order to determine the expected efficiencies for the tandem cell structures shown in Figure 1, the calculations for each of the III-V sub-cells (n-p homojunctions) were made using reported values for transport parameters such as mobilities and carrier lifetimes, as will be explained below. The parameters assumed for the III-V compounds are given in Table $1[16,17]$. The (front and back) surface recombination velocities for each IIIV sub-cell were assumed to be $\mathrm{S}=10^{3} \mathrm{~cm} / \mathrm{s}$. This is an intermediate value between passivated and non-passivated surfaces.

Table 1. Parameters used for the calculations $[16,17]$.

\begin{tabular}{lll}
\hline Respective III-V Sub-cell & InGaP & GaAs \\
\hline Lifetime n $\tau_{n}(\mathrm{~s})$ & $10^{-9}$ & $10^{-9}$ \\
Lifetime p $\tau_{p}(\mathrm{~s})$ & $10^{-9}$ & $2 \times 10^{-8}$ \\
$\begin{array}{l}\text { Diffusion coefficient } \\
\text { of electrons } D_{n}\left(\mathrm{~cm}^{2} / \mathrm{s}\right)\end{array}$ & 29 & 200 \\
$\begin{array}{l}\text { Diffusion coefficient } \\
\text { of holes } D_{p}\left(\mathrm{~cm}^{2} / \mathrm{s}\right)\end{array}$ & 1.0 & 9.2 \\
Band gap $(\mathrm{eV})$ & 1.9 & 1.43 \\
$\begin{array}{l}\text { Dielectric permittivity } \\
\text { Donor density Nd }\left(\mathrm{cm}^{-3}\right)\end{array}$ & 11.6 & 13.1 \\
Acceptor density Na $\left(\mathrm{cm}^{-3}\right)$ & $10^{17}$ & $10^{17}$ \\
$\begin{array}{l}\text { Surface recombination } \\
\text { velocities }(\mathrm{cm} / \mathrm{s})\end{array}$ & $10^{3}$ & $10^{18}$ \\
\hline
\end{tabular}

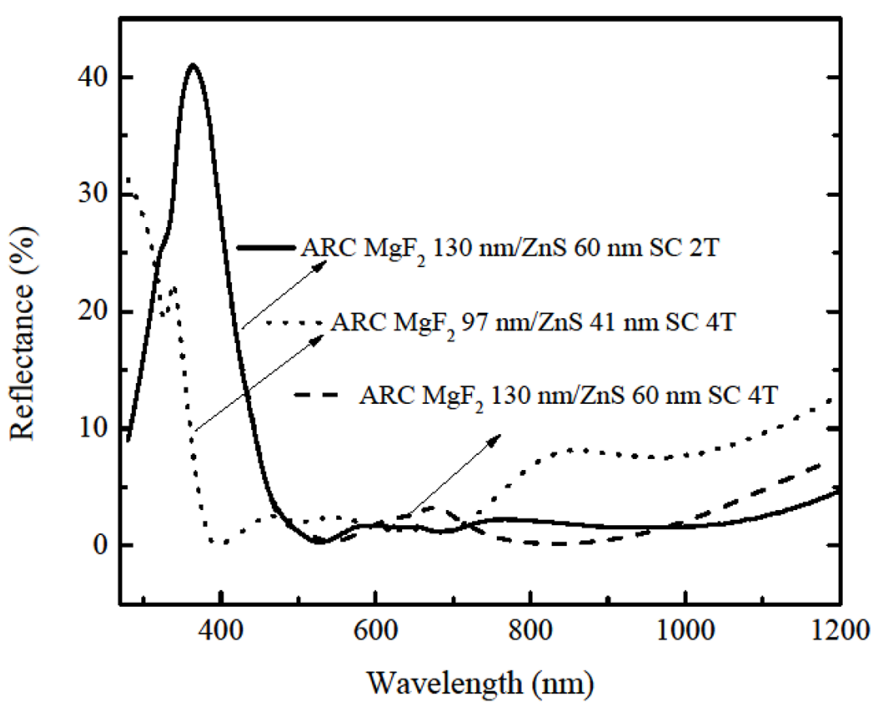

Fig. 2. Reflectance for tandem solar cells with a double layer ARC system.

In addition, previously reported optical parameters such as refraction and extinction coefficients were also taken in account to evaluate the total cell reflectance $R(\lambda)$ at each wavelength of the AM1.5 solar spectrum [18-20]. For this purpose, an optical matrix method [21] was used for the calculation of the spectral reflectance $R(\lambda)$, assuming a $\mathrm{MgF}_{2} / \mathrm{ZnS}$ anti-reflecting double layer (ARC). Figure 2 shows the results for the spectral reflectance taking in account different thicknesses for the double ARC used for these tandem cells. The thicknesses used for the calculations shown in Figure 2 are the optimized values, as will be explained below, and the thicknesses used for the experimental record efficiency InGaP/GaAs//Si tandem solar cells reported recently [14].

\subsection{III-V Top sub-cell optimization}

The InGaP and GaAs tandem homojunctions constitute the top (two-terminal) sub-cell, and they were assumed to be connected in series (through a tunnel junction), so that the photo-current (short-circuit) density for each junction should be the same. The thickness for each material is designed to satisfy this condition.

The optimization proceeded using a two-step process. In the first step, a first order approximation for the photocurrent of each sub-cell was calculated using the following equation:

$$
J_{L i}=q \int_{\lambda_{\min }}^{\lambda_{\text {gapi }}} N_{0} \exp \left(-\sum_{k=1}^{i-1} \alpha_{k} d_{k}\right)\left(1-\exp \left(-\alpha_{i} d_{i}\right)\right) d \lambda
$$

with direct bandgap absorption coefficients calculated by

$$
\alpha_{k} \approx A \sqrt{\left(\frac{h c}{\lambda}-E_{\text {gapi }}\right)} \text { and } A \approx 10^{5}\left(\mathrm{~cm}^{-1}\right)
$$




$$
\begin{aligned}
J^{\prime}{ }_{p}(\lambda)= & \frac{q N^{\prime}{ }_{0}(\lambda)(1-R(\lambda)) \alpha(\lambda) L_{p}}{\left((\alpha(\lambda))^{2} L_{p}^{2}-1\right)} \\
& \times\left\{\frac{\frac{S_{p} L_{p}}{D_{p}}+\alpha(\lambda) L_{p}-e^{-\alpha(\lambda)\left(W_{n}-x_{n}\right)}\left(\frac{S_{p} L_{p}}{D_{p}} \cosh \left(\frac{W_{n}-x_{n}}{L_{p}}\right)+\operatorname{senh}\left(\frac{W_{n}-x_{n}}{L_{p}}\right)\right)}{\frac{S_{p} L_{p}}{D_{p}} \operatorname{senh}\left(\frac{W_{n}-x_{n}}{L_{p}}\right)+\cosh \left(\frac{W_{n}-x_{n}}{L_{p}}\right)}-\alpha(\lambda) L_{p} e^{-\alpha(\lambda)\left(W_{n}-x_{n}\right)}\right\}
\end{aligned}
$$

$$
\begin{aligned}
& J_{n}^{\prime}(\lambda)= \frac{q N_{0}^{\prime}(\lambda)(1-R(\lambda)) \alpha(\lambda) L_{n}}{\left((\alpha(\lambda))^{2} L_{n}{ }^{2}-1\right)} e^{-\alpha(\lambda)\left(W_{n}+x_{p}\right)} \\
& \times\left\{\begin{array}{c}
\frac{S_{n} L_{n}}{D_{n}}\left(\cosh \frac{\left(W_{p}-x_{p}\right)}{L_{n}}-e^{-\alpha(\lambda)\left(W_{p}-x_{p}\right)}\right)+\operatorname{senh} \frac{\left(W_{p}-x_{p}\right)}{L_{n}}+\alpha(\lambda) L_{n} e^{-\alpha(\lambda)\left(W_{p}-x_{p}\right)} \\
\frac{S_{n} L_{n}}{D_{n}} \operatorname{senh} \frac{\left(W_{p}-x_{p}\right)}{L_{n}}+\cosh \frac{\left(W_{p}-x_{p}\right)}{L_{n}}
\end{array}\right\} \\
& J_{s c r}^{\prime}(\lambda)=q N^{\prime}{ }_{0}(\lambda)(1-R(\lambda)) e^{-\alpha(\lambda)\left(W_{n}-x_{n}\right)}\left[\left(1-e^{-\alpha(\lambda)\left(x_{n}+x_{p}\right)}\right)\right]
\end{aligned}
$$

where $q$ is the electron charge, $\alpha_{k}$ is the absorption coefficient, $d_{k}$ is the thickness of each junction $(k=1,2)$ above the $i^{\text {th }}$ junction, $\lambda_{\text {gapi }}$ is the wavelength corresponding to the band gap of the $i^{\text {th }}$ material $\left(\lambda_{\text {gapi }}=h c / E_{\text {gapi }}\right.$ where $h$ is the Planck's constant and $c$ is the speed of light in the air). $N_{0}$ is the photon flux density due to the AM1.5 solar spectrum. This first order approximation allowed the estimation of the required thickness for each sub-cell.

Then, in the second step (See Eqs. (3)-(5)) [22], a more realistic calculation for the photocurrent density was made considering the calculated spectral reflectance $R(\lambda)$ in the solar spectrum, where $R(\lambda)$ takes in account the effect associated to the antireflection coating.

$L_{n}$ and $L_{p}$ are the minority carrier diffusion lengths, $D_{n}$ and $D_{p}$ the diffusion coefficients, $\tau_{n}$ and $\tau_{p}$ are the minority carrier lifetimes, $W_{p}$ and $W_{n}$ are the layer thickness, $x_{p}$ and $x_{n}$ the space charge region lengths, $S_{p}$ and $S_{n}$ are the respective surface recombination velocities, and $\alpha(\lambda)$ the absorption coefficient as a function of wavelength [22]. $N^{\prime}{ }_{0}$ is the available photon flux for each sub-cell.

In addition, both the volumetric and the surface recombination are considered for the dark currents at each junction, accordingly to a previously reported analytical model [22]. This provides an improved design to our previous approach [23] because now we are also including the effects due to the depletion region in each of the III-V compound cells. This is important because a parameter that determines the photoelectric properties of a thin film solar cell is the thickness of the space charge region (depletion region) in both the p-type and n-type sides of each of the homojunctions. For this purpose, let us remember that the space-charge width in a solar cell can be calculated by means of the following expressions:

$$
\begin{aligned}
& x_{p}(V)=\frac{1}{N_{a}}\left(\frac{2 \varepsilon\left(V_{b i}-V\right)}{q\left(\frac{1}{N_{a}}+\frac{1}{N_{d}}\right)}\right)^{\frac{1}{2}} \\
& x_{n}(V)=\frac{1}{N_{d}}\left(\frac{2 \varepsilon\left(V_{b i}-V\right)}{q\left(\frac{1}{N_{a}}+\frac{1}{N_{d}}\right)}\right)^{\frac{1}{2}}
\end{aligned}
$$

where $\varepsilon$ is the dielectric permittivity of the semiconductor, $V$ is the bias voltage and $V_{b i}$ is the built-in potential. In other words, there is a variation of depletion layer thickness as a function of the applied voltage which causes a variation of both the generated photocurrent and the generationrecombination dark current densities as a function of the bias voltage. All this affects the optimized thickness for each of the sub-cells, as well as the total efficiency.

Then, for each of the junctions, the total $J$ as a function of voltage can be calculated using an equivalent model with two diodes:

$$
J_{i}=J_{L i}-J_{0 i}\left(\exp \left(\frac{q V}{V_{T}}\right)-1\right)-J_{00 i}\left(\exp \left(\frac{q V}{2 V_{T}}\right)-1\right)
$$

where $J_{0 i}$ and $J_{00 i}$ are the dark saturation currents due to diffusion and generation-recombination in the 
Table 2. Experimental J-V parameters for high efficiency HIT silicon solar cells [21].

HIT silicon solar cell characteristics [19]

\begin{tabular}{llll}
\hline & $V_{o c}$ & $J_{s c}$ & Thickness \\
HIT solar cell & $(\mathrm{mV})$ & $\left(\mathrm{mA} / \mathrm{cm}^{2}\right)$ & $\begin{array}{l}(\mathrm{cm}) \\
\end{array}$ \\
& 750 & 39.5 & $98 \times 10^{-4}$ \\
\hline
\end{tabular}

space-charge region, respectively. They are given by

$$
\begin{aligned}
J_{0 i}= & \frac{q D_{p} p_{0}}{L_{p}}\left(\frac{\frac{S_{p} L_{p}}{D_{p}} \cosh \frac{\left(W_{n}-x_{n}\right)}{L_{p}}+\sinh \frac{\left(W_{n}-x_{n}\right)}{L_{p}}}{\left.\frac{S_{p} L_{p}}{D_{p}} \sinh \frac{\left(W_{n}-x_{n}\right)}{L_{p}}+\cosh \frac{\left(W_{n}-x_{n}\right)}{L_{p}}\right)}\right. \\
& +\frac{q D_{n} n_{0}}{L_{n}}\left(\frac{\frac{S_{n} L_{n}}{D_{n}} \cosh \frac{\left(W_{p}-x_{p}\right)}{L_{n}}+\sinh \frac{\left(W_{p}-x_{p}\right)}{L_{n}}}{\frac{S_{n} L_{n}}{D_{n}} \sinh \frac{\left(W_{p}-x_{p}\right)}{L_{n}}+\cosh \frac{\left(W_{p}-x_{p}\right)}{L_{n}}}\right)
\end{aligned}
$$

and

$$
J_{00 i}=q\left(\frac{x_{n} n_{i, n}}{\tau_{p}}+\frac{x_{p} n_{i, p}}{\tau_{n}}\right)
$$

where, $n_{i}$ is the intrinsic carrier density for each semiconductor.

In addition, the photogenerated current density $J_{\mathrm{Li}}$ should include the photo-generated carriers in this spacecharge region (see Eq. (5)) [22]. All these effects become important for thin film solar cells.

\subsection{Bottom sub-cell characteristics}

The bottom sub-cell will be assumed to be a typical heterojunction silicon HIT solar cell. The experimental J-V parameters used for the HIT bottom sub-cells under the AM1.5 spectrum [24], are given in Table 2. The corresponding dark saturation current density $J_{0}$ was estimated from the $J_{s c}$ and $V_{o c}$ values given in Table 2, assuming an ideal exponential J-V curve for this kind of solar cells, since they are limited by carrier diffusion.

Notice that such silicon solar cells will generate a reduced photo-current density when they are stacked below the above III-V sub-cells. However, ideally their dark current characteristics will not be modified. Then, when such a silicon solar cell is used for the three-junctions tandem cell, the expected photo-current density $J_{L}$ can be estimated using the following procedure. $J_{L}$ for the silicon cell (under the III-V sub-cell) was approximated by the following expression:

$$
J_{L}=q \int_{\lambda_{\text {GaAs }}}^{\lambda_{\text {silicon }}} N^{\prime}{ }_{0}(\lambda)(1-R(\lambda))(1-\exp (-\alpha d)) d \lambda
$$

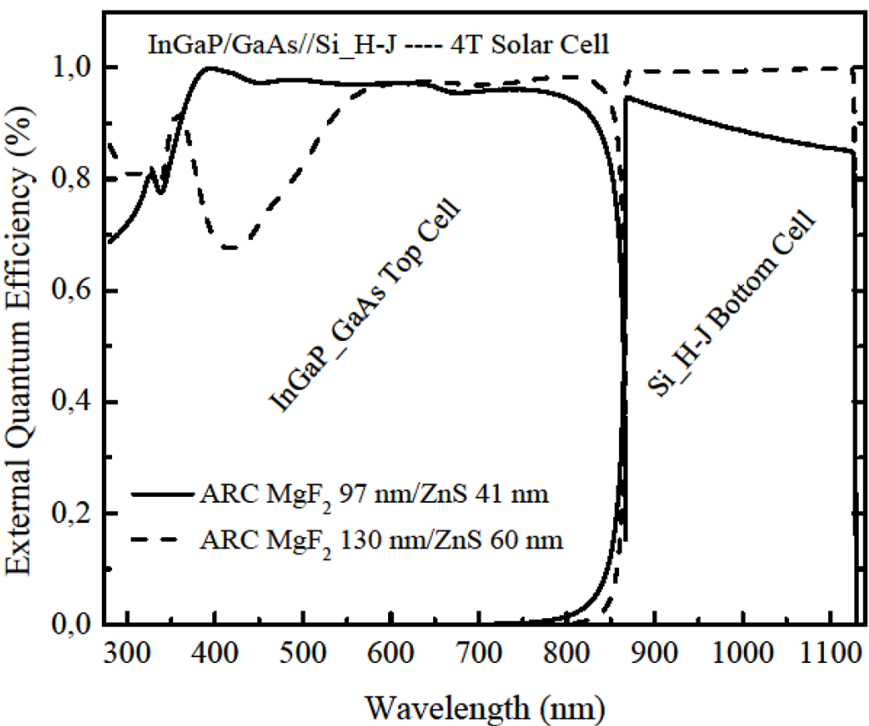

Fig. 3. External quantum efficiency for the four-terminal cell with a double layer ARC system.

where $\alpha$ is the absorption coefficient for crystalline silicon and $d$ is the reported thickness for the assumed high efficiency HIT solar cell $(98 \mu \mathrm{m})$ [25]. The full J-V curve for the silicon HIT solar cell, under the III-V compound subcell, can be calculated from this photo-current density $J_{L}$ and the dark saturation current density $J_{0}$ determined as explained above.

\section{Two-terminal tandem solar cells}

The use of the model described in the previous section, and the mentioned considerations corresponding to each of the materials involved, enabled the calculation of the output parameters and characteristic contributions of each of the sub-cells of a two-terminal tandem cell. In this case, the thickness of each absorber layer was chosen so that the illumination current densities are the same for each sub-cell (InGaP/GaAs) and the silicon HIT cell. Thus, the procedure is similar to what was done for the III-V compound junctions in tandem. In this case, the appropriate ARC thicknesses were chosen to cause the largest photo-current density for the whole cell. Then, the thickness for each of the III-V compound sub-cells are selected to generate a constant photocurrent density for the whole tandem cell structure.

\section{Results}

\subsection{Optimized four-terminal tandem solar cells}

The external quantum efficiencies for each sub-cell as a function of wavelength are shown in Figure 3 for the different ARC thicknesses considered. The thickness of each absorber layer was chosen so that the illumination current densities reach the maximum value for each subcell. In this case, the top and bottom junctions were 


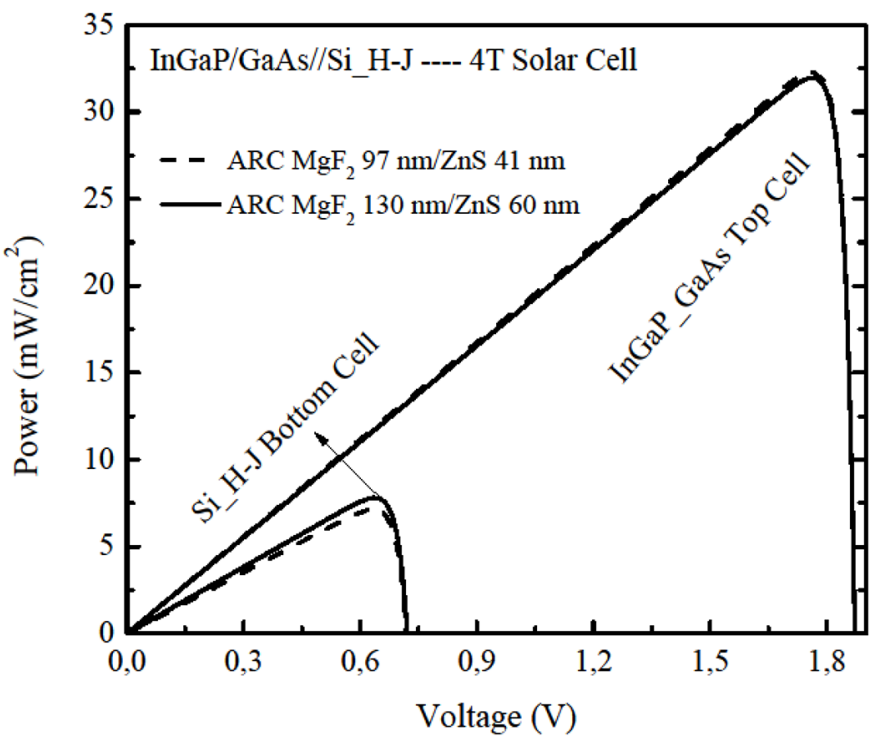

Fig. 4. Power versus voltage for each sub-cell in the fourterminal tandem cell.

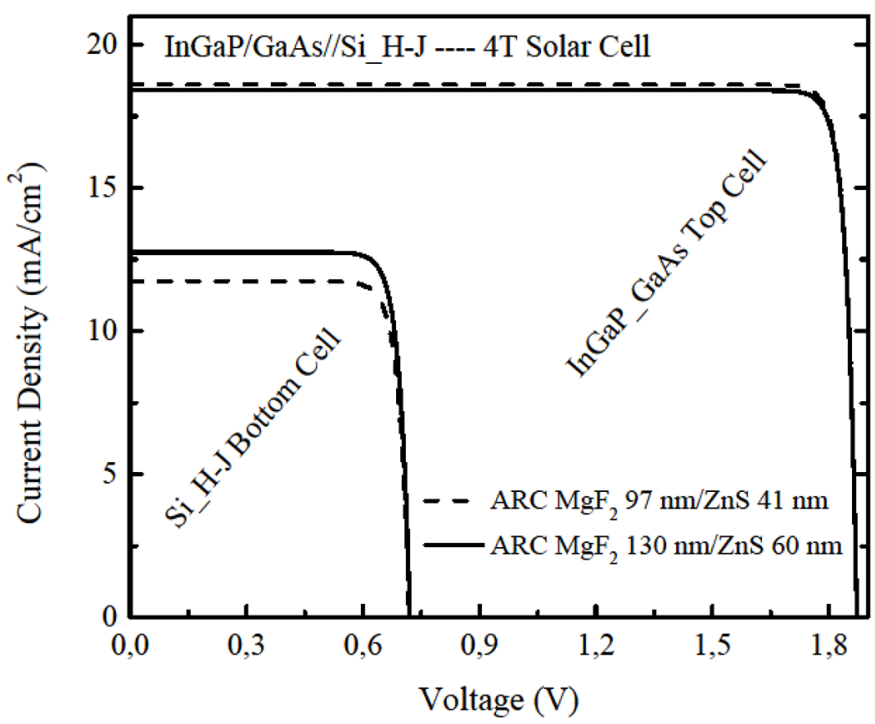

Fig. 5. Current versus voltage for each sub-cell in the fourterminal tandem cell.

Table 3. Calculated illumination current density, open circuit voltage, fill factor and power conversion efficiency for each of the sub-cells and the four-terminal tandem cells.

4-Terminal cell with $\mathrm{MgF}_{2} 130 \mathrm{~nm} / \mathrm{ZnS} 60 \mathrm{~nm}$ ARC System

\begin{tabular}{llllll}
\hline Solar cells & $J_{s c}\left(\mathrm{~mA} / \mathrm{cm}^{2}\right)$ & $V_{o c}(\mathrm{mV})$ & $F F(\%)$ & $\eta(\%)$ & Total $\eta(\%)$ \\
GaInP_220 nm/GaAs_1800 nm// & 18.4 & 1872 & 92.9 & 32.0 & 39.8 \\
Silicon-HJ & 12.8 & 720 & 84.6 & 7.8 & \\
\hline \multicolumn{7}{r}{ 4-Terminal cell with $\mathrm{MgF}_{2}$} & $97 \mathrm{~nm} / \mathrm{ZnS} \mathrm{41} \mathrm{nm} \mathrm{ARC} \mathrm{system}$ & & \\
\hline Solar cells & $J_{s c}\left(\mathrm{~mA} / \mathrm{cm}^{2}\right)$ & $V_{o c}(\mathrm{mV})$ & $F F(\%)$ & $\eta(\%)$ & Total $\eta(\%)$ \\
GaInP_220 nm/GaAs_1800 nm// & 18.6 & 1872 & 92.8 & 32.3 & 39.5 \\
Silicon-HJ & 11.7 & 718 & 85.7 & 7.2 & \\
\hline
\end{tabular}

The calculations include light reflection for a cell with $\mathrm{MgF}_{2} / \mathrm{ZnS}$ as ARC.

assumed to have absorber layers with bandgaps of $1.9 \mathrm{eV}$ (InGaP), $1.43 \mathrm{eV}(\mathrm{GaAs})$, and $1.08 \mathrm{eV}(\mathrm{Si})$, respectively. Figures 4 and 5 show the calculated $\mathrm{P}-\mathrm{V} / \mathrm{J}-\mathrm{V}$ characteristics for each of the sub-cells. From these, the efficiencies for the sub-cells can be determined. Ideally, the total efficiency will be the sum of the sub-cell efficiencies. Unlike the two-terminal solar cells where the current density of the junctions must be the same, in the four-terminal cell (where the tandem is mechanically made) the maximum possible photocurrent density can be achieved for each sub-cell.

In Table 3, the optimized efficiency for the ARC used for the reported experimental record efficiency cells [14] is also given. Notice that in this case, the calculated efficiency $(39.5 \%)$ is slightly less as compared to cells with our optimized ARC which gives a total efficiency of $\mathbf{3 9 . 8 \%}$. The experimental record efficiency for this kind of cells, under the AM1.5 solar spectrum, is around $\mathbf{3 5 . 9 \%}$ [14]. Therefore, in accordance with the above results, we still can expect some improvement for this kind of solar cells in the near future.

\subsection{Optimized two-terminal tandem solar cells}

The EQE results for the two-terminal tandem cell are shown in Figure 6 for an ARC with respective optimum layers of 130 and $60 \mathrm{~nm}$. The contribution of each sub-cell is also shown in this figure. As explained before, the ARC coating thickness was chosen so that the cell achieves the largest photocurrent density. The J-V curve can be calculated from the two diodes in series model for each of the InGaP/GaAs and Si sub-cells, as shown in Figure 7. The thickness of each absorber layer was chosen so that the illumination current densities are the same for each sub-cell. In this case, the maximum efficiency was obtained when the top and bottom junctions had absorber layers with thicknesses of $166 \mathrm{~nm}$ (InGaP), $360 \mathrm{~nm}(\mathrm{GaAs})$, and $98 \mu \mathrm{m}(\mathrm{Si})$, respectively. The total tandem cell conversion efficiency would be $39.6 \%$ as given in Table 4 . This value is comparable with the expected efficiency for the optimized four-terminal tandem cell. 


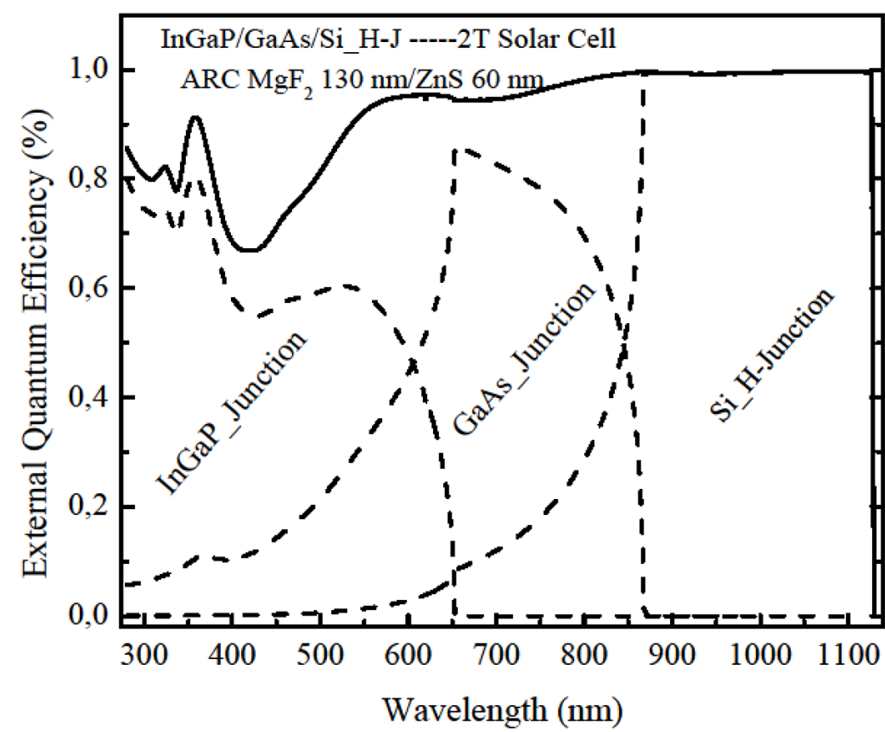

Fig. 6. External quantum efficiency for the two-terminal cell with an optimum a double ARC system.

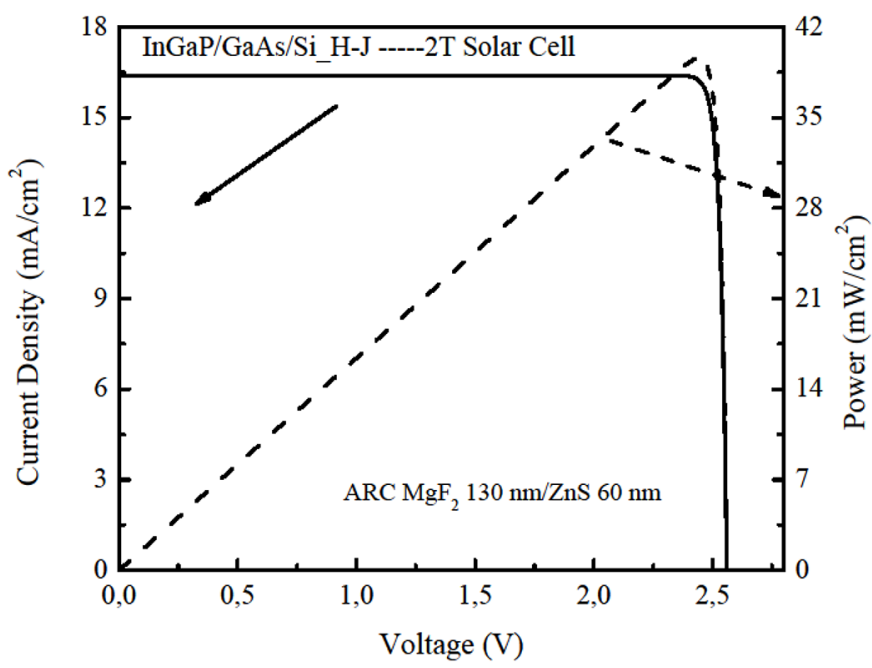

Fig. 7. Current and power versus voltage curves for the twoterminal tandem cell.

Table 4. Calculated illumination current density, open circuit voltage, fill factor and power conversion efficiency for the two-terminal tandem cells.

2-Terminal cell with $\mathrm{MgF}_{2} 130 \mathrm{~nm} / \mathrm{ZnS} 60 \mathrm{~nm}$ ARC system

\begin{tabular}{lllll}
\hline Solar cells & $J_{s c}\left(\mathrm{~mA} / \mathrm{cm}^{2}\right)$ & $V_{o c}(\mathrm{mV})$ & $F F(\%)$ & Total $\eta(\%)$ \\
GaInP_166 nm/GaAs_360 nm//Silicon-HJ & 16.4 & 2560 & 94.3 & 39.6 \\
\hline
\end{tabular}

The calculations include light reflection for a cell with $\mathrm{MgF}_{2} / \mathrm{ZnS}$ as ARC.

\subsection{Comparison with our previous results}

The maximum efficiency expected for the four-terminal tandem cell in our previous work [23] was $41.7 \%$, while the efficiency achieved in this work is $39.8 \%$, as explained above. This difference is explained by the effects due to the space-charge regions in each of the III-V compound subcells. In addition, a double anti-reflection coating was used here which allows for a larger sunlight absorption, compensating some of the loss due to the recombination in the depletion regions. However, our calculations suggest that by optimizing the sub-cell layer thicknesses it is still possible to achieve a higher efficiency than the recent record reported [14].

\section{Conclusion}

By including a double ARC and the effects due to the space-charge regions in the III-V compound sub-cells, InGaP/GaAs//Silicon tandem solar cells were optimized for each of the two or four-terminal configurations. The four-terminal tandem cell efficiency at 1 sun should reach around $39.8 \%$ when the appropriate thicknesses for each layer, including the anti-reflection coating, are used. In the specific case of $\mathrm{MgF}_{2} / \mathrm{ZnS}$ as ARC, the optimum thickness is 130 and $60 \mathrm{~nm}$ respectively, while the calculated optimum InGaP thickness is $220 \mathrm{~nm}$ and GaAs optimum thickness is $1800 \mathrm{~nm}$. The results shown here can be compared with the experimental record efficiency already achieved $(35.9 \%)$ for this type of solar cells [14]. Then, it is still possible to improve this record efficiency.

\section{Author contribution statement}

S. Torres-Jaramillo made the calculations and wrote the paper draft; R. Bernal-Correa developed the original code and supervised the calculations; A. Morales-Acevedo proposed the research and the methodology, validated the results and wrote the final version of the paper.

\section{References}

1. S. Almosni et al., Sci. Technol. Adv. Mat. 19, 336 (2018)

2. A. Tombak, T. Kilicoglu, Y.S. Ocak, Renew. Energ. 146, $1465(2020)$

3. C. Yang et al., Sol. Energy 195, 121 (2020)

4. I.E. Tinedert et al., Optik 208, 164112 (2020)

5. G. Liyanage et al., ACS Appl. Energy Mater. 2, 5419 (2019)

6. J. Dreon et al., Nano Energy 70, 104495 (2020)

7. H. Sai et al., Prog. Photovolt. Res. Appl. 27, 1061 (2019)

8. O. Höhn et al., IEEE J. Photovolt. 9, 1625 (2019) 
9. B. Jeco et al., J. Photon. Energy 8, 022602 (2018)

10. P. Caño et al., Sol. Energy Mat. Sol. C 205, 110246 (2020)

11. E.L. Warren et al., in Proceedings 44th PVSC, Washington D.C., USA, 2017, edited by A. Reinders (IEEE Xplore, 2018), p. 2488

12. M. Feifel et al., IEEE J. Photovolt. 8, 1590 (2018)

13. Q. Han et al., Science 361, 904 (2018)

14. S. Essig et al., Nat. Energy 2, 17144 (2017)

15. J.F. Geisz et al., Nat. Energy 5, 326 (2020)

16. R. Ganouni, M. Talbi, H. Ezzaouia, J. Fundam. Appl. Sci. 9, 756 (2017)

17. G. Lin et al., III-V Multi-Junction Solar Cells, edited by S. Pyshkin, J. Ballato, (Optoelectronics, Intech, 2013)
18. https://www.pvlighthouse.com.au/refractive-index-library (2020)

19. https://www.filmetrics.com/refractive-index-database (2020)

20. https://refractiveindex.info (2020)

21. R. Bernal-Correa et al., Mat. Sci. Semicon. Pro. 37, 57 (2015)

22. A. Acevedo-Luna et al., J. Appl. Res. Technol. 15, 599 (2017)

23. R. Bernal-Correa, S. Torres-Jaramillo, A. Morales-Acevedo, in Proceedings 46th PVSC, Chicago, IL, USA, 2019, edited by S. Kurtz (IEEE Xplore, 2020), p. 0989

24. M. Taguchi et al., IEEE J. Photovolt. 4, 96 (2014)

25. https://www.pveducation.org/es/fotovoltaica/dispositivossemiconductores/coeficiente-de-absorcion (2020)

Cite this article as: Santiago Torres-Jaramillo, Roberto Bernal-Correa, Arturo Morales-Acevedo, Improved design of InGaP/ GaAs//Si tandem solar cells, EPJ Photovoltaics 12, 1 (2021) 